\title{
Noninvasive intracranial pressure monitoring methods: a critical review
}

\author{
Métodos de monitorização não invasivos da pressão intracraniana: uma revisão crítica \\ Fabiano Moulin de MORAES ${ }^{1}$, Gisele Sampaio SILVA'
}

\begin{abstract}
Background: Intracranial pressure (ICP) monitoring has been used for decades in management of various neurological conditions. The gold standard for measuring ICP is a ventricular catheter connected to an external strain gauge, which is an invasive system associated with a number of complications. Despite its limitations, no noninvasive ICP monitoring (nilCP) method fulfilling the technical requirements for replacing invasive techniques has yet been developed, not even in cases requiring only ICP monitoring without cerebrospinal fluid (CSF) drainage. Objectives: Here, we review the current methods for nilCP monitoring. Methods: The different methods and approaches were grouped according to the mechanism used for detecting elevated ICP or its associated consequences. Results: The main approaches reviewed here were: physical examination, brain imaging (magnetic resonance imaging, computed tomography), indirect ICP estimation techniques (fundoscopy, tympanic membrane displacement, skull elasticity, optic nerve sheath ultrasound), cerebral blood flow evaluation (transcranial Doppler, ophthalmic artery Doppler), metabolic changes measurements (near-infrared spectroscopy) and neurophysiological studies (electroencephalogram, visual evoked potential, otoacoustic emissions). Conclusion: In terms of accuracy, reliability and therapeutic options, intraventricular catheter systems still remain the gold standard method. However, with advances in technology, noninvasive monitoring methods have become more relevant. Further evidence is needed before noninvasive methods for ICP monitoring or estimation become a more widespread alternative to invasive techniques.
\end{abstract}

Keywords: Brain Injury; Intracranial Hypertension; Stroke; Intracranial Pressure; Head Trauma.

\section{RESUMO}

Introdução: O uso da monitorização da pressão intracraniana (PIC, em sua sigla em inglês) é adotado há décadas no manejo de diversas condições neurológicas. O padrão ouro atual é a monitorização invasiva intraventricular, que está relacionada a inúmeras complicações. Apesar dessas limitações, até o momento nenhum método de monitorização não invasiva (niPIC, em sua sigla em inglês) conseguiu substituir a técnica invasiva. Objetivos: Revisar os métodos não invasivos de monitorização da PIC. Métodos: As diferentes modalidades e abordagens foram agrupadas de acordo com o mecanismo utilizado para detectar elevação da PIC ou suas consequências. Resultados: As técnicas descritas foram: o exame físico, neuroimagem (tomografia computadorizada e ressonância magnética de crânio), estimativas indiretas da PIC (fundoscopia, deslocamento da membrana timpânica, elasticidade craniana), avaliação do fluxo cerebral (doppler transcraniano e doppler da artéria oftálmica), alterações metabólicas (Espectroscopia próxima do infravermelho) e estudos neurofisiológicos (eletroencefalograma, potencial evocado visual e emissões otoacústicas). Conclusão: Considerando a acurácia, confiabilidade e opções terapêuticas, o sistema de cateteres intraventricular ainda permanece como padrão ouro. No entanto, com os avanços tecnológicos, os métodos não invasivos têm se tornados mais relevantes. Mais evidências são necessárias antes que essas modalidades de monitorização ou estimativas não invasivas se tornem uma alternativa mais robusta às técnicas invasivas.

Palavras-chave: Lesão Encefálica; Hipertensão Intracraniana; Acidente Vascular Cerebral; Pressão Intracraniana; Trauma Craniano.

\section{INTRODUCTION}

Intracranial pressure (ICP) monitoring has been used for decades in management of various neurological conditions (Table 1) and has become a staple of neurocritical care $^{1}$. While management of ICP is of clear benefit, there is no consensus in the literature about whether ICP monitoring provides any clinical benefit, compared with management based only on the patient's neurological examination, imaging findings and the clinician's judgment ${ }^{2,3}$. While some studies have shown that ICP monitoring is associated with improved survival rates, others have suggested that this not only is fruitless but also may, in fact, lead to worse clinical outcomes, including increased mortality, longer hospitalization,

\footnotetext{
1 Universidade Federal de São Paulo, Departamento de Neurologia e Neurocirurgia, Unidade Neurovascular, São Paulo SP, Brazil.

Fabiano Moulin de MORAES (ID) https://orcid.org/0000-0002-4838-2840; Gisele Sampaio SILVA (iD) https://orcid.org/0000-0002-3247-3123

Correspondence: Fabiano Moulin de Moraes; E-mail: fabianomoulin@yahoo.com.br

Conflict of interest: There is no conflict of interest to declare.

Authors' contributions: FMM: study conception and design, acquisition of data, analysis and interpretation of data, drafting of manuscript. GSS: study conception and design, critical review.

Received on June 28, 2020; Received in its final form on September 05, 2020; Accepted on September 16, 2020.
} 
increased complication rates and increased hospitalization costs, compared with a non-ICP monitoring approach in patients with traumatic brain injury (TBI) ${ }^{4}$. The only randomized trial assessing the effect of invasive ICP monitoring on clinical outcomes, conducted by Chesnut et al. ${ }^{5}$ among patients with severe TBI, found that there was no significant difference in six-month mortality. These results indicate that there is still room for improvement of clinical management of ICP monitoring findings, which could assist in better clinical decisions and improved outcomes for critically ill patients ${ }^{2,4}$.

A ventricular catheter connected to an external strain gauge is the gold standard for measuring ICP. This is an invasive system associated with a number of complications, including hemorrhage, obstruction, mispositioning, infection and loss of accuracy for asymmetric hemispheric lesions, besides requiring a neurosurgical procedure ${ }^{6,7}$. However, despite its limitations, no noninvasive ICP monitoring (niICP) method fulfilling the technical requirements for replacing invasive techniques has yet been developed, not even in cases requiring only ICP monitoring without cerebrospinal fluid (CSF) drainage ${ }^{8,9}$.

Here, we review the current methods for monitoring niICP and the neurological consequences of increased ICP, such as reduced cerebral blood flow (CBF) and metabolic changes ${ }^{10}$. The different methods and approaches were grouped according to the mechanism used for detecting elevated ICP or its associated consequences. The main approaches reviewed here were: physical examination, brain imaging (magnetic resonance imaging [MRI], computed tomography [CT] and optic nerve sheath ultrasound [ONS-US]), indirect ICP estimation techniques (fundoscopy, tympanic membrane displacement and skull elasticity), cerebral blood flow velocity (transcranial Doppler [TCD] and ophthalmic artery Doppler), metabolic changes measurements (near-infrared spectroscopy [NIRS]) and neurophysiological studies (electroencephalogram [EEG], visual evoked potential [VEP] and otoacoustic emissions) (Table 2). Although this topic has been addressed by other authors before, we present an updated review of the literature with a discussion of new methods not previously evaluated in narrative reviews.

\section{Physical examination}

Because patients requiring ICP monitoring usually have severe and acute neurological conditions, neurological

Table 1. Potential indications for intracranial pressure monitoring.

\begin{tabular}{l}
\hline Traumatic brain injury \\
Intracranial hemorrhage \\
Subarachnoid hemorrhage \\
Cerebral edema \\
Hydrocephalus \\
Hepatic encephalopathy \\
Cerebral ischemia \\
\hline
\end{tabular}

parameters in such patients are often derived from the Glasgow Coma Scale (GCS), which is the most common scoring system used in these settings. Only three physical examination findings, which had been evaluated in an adequate number of relevant studies and were included in a meta-analysis, correlated with increased ICP: pupillary dilation; motor posturing, defined by GCS motor score $\leq 3$; and decreased level of consciousness, defined by total GCS $\leq 8$. The presence of pupillary dilation had a sensitivity of $28.2 \%$ and specificity of $85.9 \%$ for the diagnosis of elevated ICP, whereas the presence of motor posturing had a sensitivity of $54.3 \%$ and specificity of $63.6 \%$. Lastly, a decreased level of consciousness had a sensitivity of $75.8 \%$ and specificity of $39.9 \%$ for the diagnosis of elevated ICP ${ }^{1}$.

\section{Neuroimaging}

\section{Computed tomography and magnetic resonance imaging of the brain}

$\mathrm{CT}$ and MRI of the brain are routinely used for diagnosing neurological disorders and can provide qualitative information about ICP. A variety of gross anatomical changes associated with elevated ICP can be detected using brain imaging techniques, including lateral ventricle compression, midline shift, ventricular dilation and loss of cortical-subcortical

Table 2. Noninvasive indications for intracranial pressure monitoring methods.

\section{Methods studied}

Physical examination

Neuroimaging

CT and MRI of the brain

US of the optic nerve sheath

Metabolic changes

Near-infrared spectroscopy

Indirect ICP monitoring

Skull elasticity

Anterior fontanelle pressure

Venous ophthalmodynamometry

Acoustic elasticity

Pupillometry

Tympanic membrane displacement

Metabolic changes

Near-infrared spectroscopy

Neurophysiology

Electroencephalogram

Visual evoked potential

Otoacoustic emissions

Cerebral blood flow

Transcranial Doppler

ICP: indications for intracranial pressure. 
differentiation ${ }^{11,12}$ (Figures 1A and 1B). Most CT-based studies have been conducted on patients with TBI, and the Marshall classification is the most commonly used classification of head injury, based primarily on CT findings ${ }^{13}$ (Table 3). However, it is worth emphasizing that most brain injury rating scales were designed for prognostic purposes and not necessarily for ICP monitoring. The presence of other CT and MRI signs in the setting of brain injury, suggestive of raised ICP, has also been used to guide the management of elevated ICP (Table 4) ${ }^{14}$.

A normal brain $\mathrm{CT}$ at admission among patients with TBI does not rule out the risk of either early intracranial hypertension or possible development of elevated ICP,

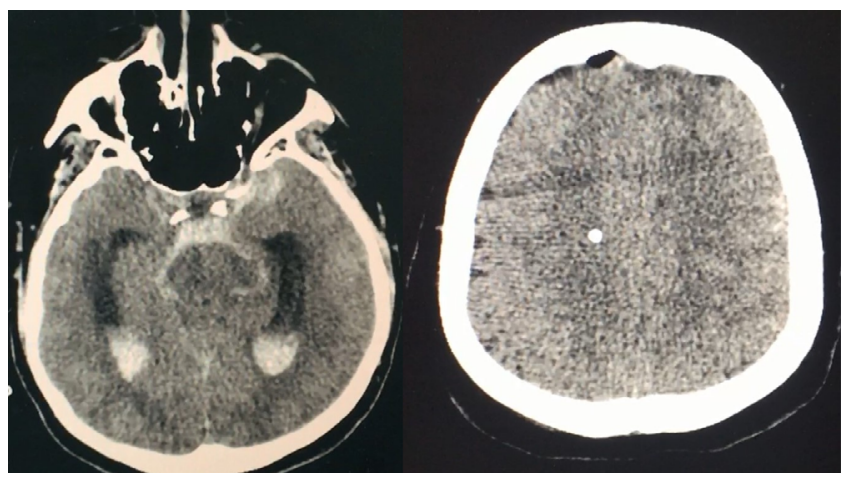

Figure 1. Computed tomography findings in intracranial hypertension (A) loss of cortical-subcortical differentiation and cortical subarachnoid hemorrhage. (B) temporal horn dilation and cisternal subarachnoid hemorrhage.

Table 3. Marshall scale.

\begin{tabular}{|c|c|}
\hline Type & Types of abnormalities on CT scanning \\
\hline । & No visible pathological condition on CT scan \\
\hline II & $\begin{array}{l}\text { Cisterns present with midline shift } 0-5 \mathrm{~mm} \text {; } \\
\text { no lesion }>25 \mathrm{~mL}\end{array}$ \\
\hline III & $\begin{array}{l}\text { Cisterns compressed or absent with midline } \\
\text { shift } 0-5 \mathrm{~mm} \text {; no lesion }>25 \mathrm{~mL}\end{array}$ \\
\hline IV & Midline shift >5 mm; no lesion $>25 \mathrm{~mL}$ \\
\hline V & Any lesion surgically evacuated \\
\hline $\mathrm{VI}$ & Lesion $>25 \mathrm{~mL}$ not surgically evacuated \\
\hline
\end{tabular}

Table 4. Computed tomography/magnetic resonance imaging findings suggestive of elevated indications for intracranial pressure.

1) Diffuse sulcal effacement

2) Effacement of basal cisterns

3) Hydrocephalus defined as:

Both temporal horns $>2 \mathrm{~mm}$

Evans' index*

4) Midline shift $>5 \mathrm{~mm}$

5) Transtentorial or uncal herniation

*The Evans' index is the ratio of maximum width of the frontal horns of the lateral ventricles, divided by the maximum internal diameter of the skull at the same level, used in axial computed tomography and magnetic resonance imaging images. with predictive values ranging from 0 to $88 \%{ }^{15}$. A small study demonstrated that it was possible to differentiate between normal and elevated ICP using a CT-determined ratio of CSF volume to total intracranial volume, with a predictive accuracy of $67 \%^{8,11}$. However, CT-based criteria have high specificity but low sensitivity, and thus high false-negative rates ${ }^{11}$.

MRI is more sensitive but rarely available and more time consuming than CT. Thus, it is not widely applied for ICP monitoring. In a small pilot study, an MRI-based technique for estimating ICP by assessing net transcranial blood and CSF flow was able to differentiate between patients with normal or elevated $\mathrm{ICP}^{12}$. An elastance index was derived from the ratio of intracranial pressure to volume change. Briefly, pulsatile arterial, venous and CSF flow in and out of the cranial vault during the cardiac cycle causes a small volume change that was measured. The elastance index correlated extremely well with the invasively measured ICP $\left(\mathrm{r}^{2}=0.965\right.$; $\mathrm{p}<0.005)$. However, care is required in selecting representative images on slides and a representative blood vessel, and the technique offers only a picture of ICP within a particular time frame ${ }^{12}$.

In short, even though neuroimaging techniques continue to be used qualitatively, these methods are currently not sufficiently reliable as monitoring tools for elevated $\mathrm{ICP}^{16}$.

\section{Optic nerve sheath diameter}

At the point at which the optic nerve exits the intracranial space into the orbit, it is still surrounded by the dural sheath. As such, the subarachnoid space (SAS) surrounding the nerve is contiguous with the intracranial subarachnoid space. Elevation of ICP can transmit through the CSF in the subarachnoid space, leading to dilation of the optic nerve sheath (ONS), which can be detected using transocular ultrasonography ${ }^{14,17}$.

Several studies have demonstrated a correlation between invasively measured ICP and ultrasonographic ONS diameter (ONSD) measurements, with overall sensitivity and specificity of 0.95 and 0.92 for detecting elevated ICP, depending on the cutoff for detection of raised ICP, which ranges from $4.8 \mathrm{~mm}^{14}$ to $5.6 \mathrm{~mm}^{18}$. A few reasons for such variations have been put forward. One is that the there are two different measurement techniques: coronal and axial techniques, with different accuracies. The coronal technique presents less variability, but the axial method provides a better estimate of ICP. A second reason is that studies have either averaged measurements between eyes or chosen to evaluate the highest measurement between the eyes, which naturally creates the discrepancies found in the literature ${ }^{18}$.

At present, this variation in the optimal ONSD cutoff makes a formal meta-analysis approach impractical ${ }^{16}$. The ONSD is measured at a depth of $3 \mathrm{~mm}$ from the posterior pole of the globe, as this point is most reflective of the changes in ICP (Figure 2). While intra and interobserver 
variability seem to be lower than that of transcranial Doppler (TCD), this method cannot be used in patients with face trauma or lesions of the orbit such as Grave's disease and sarcoidosis. Additionally, there is some evidence that the specificity of ONSD declines when there are acute fluctuations in $\mathrm{ICP}^{17}$. Nevertheless, ONSD measurements seem to be useful as a screening test for ICP in settings where invasive monitoring is not promptly available. Other ophthalmological approaches such as optical coherence tomography (OCT) have also been evaluated for ICP measurement ${ }^{19}$. The ONSD can also be measured using CT and MRI, but the accuracy of measurements by these two methods is lower ${ }^{20}$.

\section{Cerebral blood flow evaluation}

\section{Transcranial Doppler}

In the neurocritical setting, transcranial Doppler (TCD) is most commonly used as a tool for monitoring

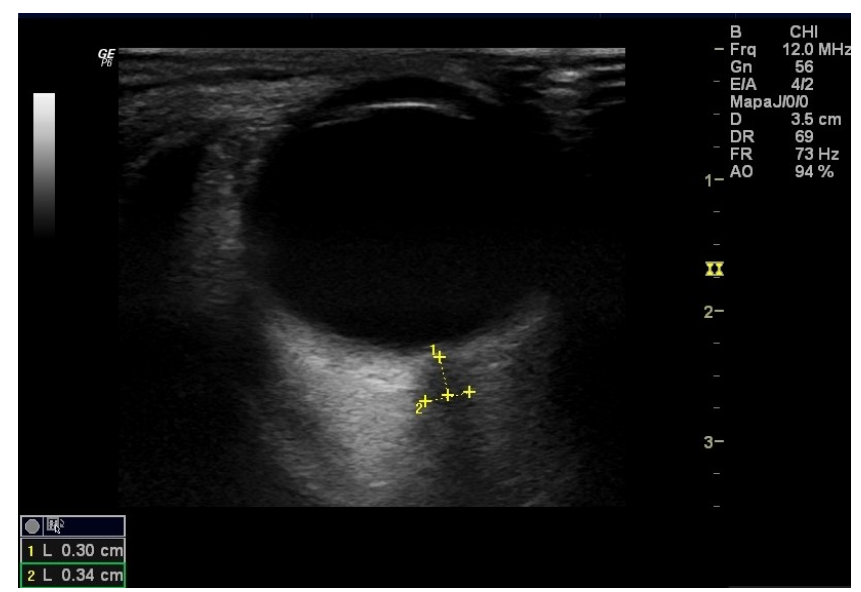

Figure 2. Optic nerve sheath and the globe are evident. The optic nerve sheath is a linear hypoechoic structure posterior to the globe. Line 1 identifies the site of optic nerve sheath diameter measurement $0.3 \mathrm{~cm}$ behind the retina. Line 2 measures the optic nerve sheath diameter $(0.34 \mathrm{~cm}$ in this case). changes in cerebral blood flow (CBF) velocity in the setting of subarachnoid hemorrhage (SAH) and its complications, including vasospasm ${ }^{21}$. A number of models using TCD-derived parameters have been used to assess correlations with invasively measured ICP ${ }^{22}$. These models have used measurements of flow velocity (FV) in the middle cerebral artery (MCA), arterial blood pressure and pulsatility index $(\mathrm{PI})^{23}$. PI is derived from the TCD waveform and is defined as the difference between systolic and diastolic flow velocities, divided by the mean FV. Wakerley et al. ${ }^{24}$ developed a formula to predict ICP using PI - ICP $=10.93$ $\times$ PI -1.28 (Figure 3 ). Some studies have shown good correlation between ICP and PI values in patients with TBI, with sensitivity and specificity of 0.89 and 0.92 , respectively, for detecting elevated ICP ${ }^{23}$.

Other studies have reported more modest results. Zweifel et al. ${ }^{25}$ prospectively analyzed a cohort of 290 patients with TBI and found a poor correlation between PI and ICP $(0.31 ; p=0.001)$. They concluded that the value of PI for assessing ICP was limited. On the other hand, Schmidt et al. ${ }^{26}$ applied a black-box mathematical model for niICP assessment with good results. A recent prospective study found that using a model that combined all TCD-derived data was superior to a model in which these data were accessed individually for estimating ICP, with a correlation coefficient of $\mathrm{r}=0.47(\mathrm{p}<0.05)$ and an area under the curve of $0.73(\mathrm{p}<0.05)$. However, TCD has some limitations: it requires training and repetitive exercise; there is intra and interobserver variability; it is not useful for patients requiring continuous monitoring; and it cannot be used on $10-15 \%$ of the patients due to a lack of bone window ${ }^{27}$.

Other methods using Doppler technology include venous transcranial Doppler ${ }^{28}$ and ophthalmic artery Doppler ${ }^{29}$, but few studies have been conducted and both of these techniques have technical difficulties that prevent their widespread adoption into clinical care.

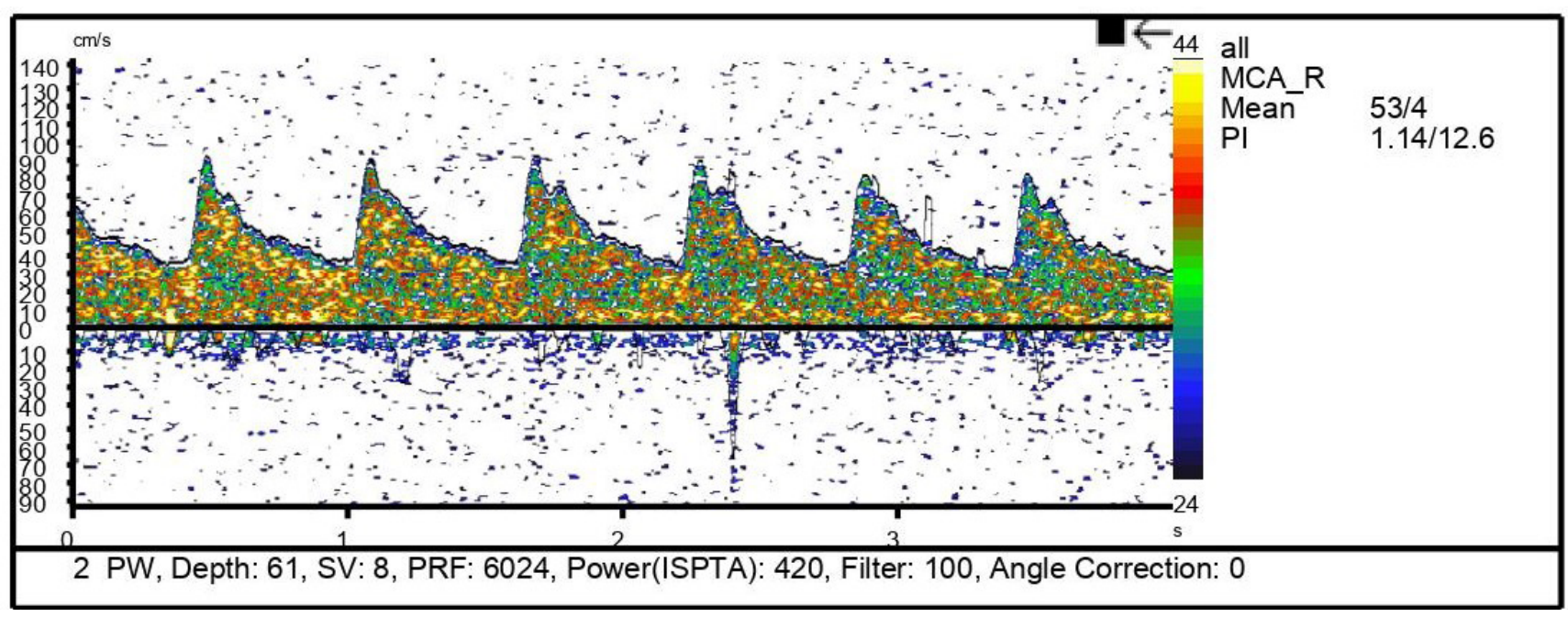

Figure 3. Transcranial Doppler measurement of right middle cerebral artery flows, demonstrating a PI of 1.26. 


\section{Metabolic changes}

\section{Near-infrared spectroscopy}

Near-infrared spectroscopy (NIRS) is a noninvasive technology that has been under development for assessment of ICP-related alterations in cerebral oxygenation ${ }^{30}$. NIRS sensors emit near-infrared (NIR) light onto the surface of the head and work on the principle of differential absorption of light in the vicinity of the infrared spectrum to detect changes in oxygen and hemoglobin concentration. Changes to the underlying tissue characteristics affect light absorption and diffusion, and spectral analysis can be used to garner information about tissue state and estimated intracranial oxygen saturation, which consequently reflects brain metabolism. This can also be used to detect changes in brain tissue oxygenation, cerebral blood volume and cerebral blood flow ${ }^{30}$.

Even though NIRS has been successfully used for monitoring oxygenation in various procedures, its reduced accuracy as a result of the effects of scalp and skull injury, as well as possible pathological changes in baseline saturation, has made this technology unreliable for widespread use ${ }^{31}$. Additionally, it cannot be used to estimate absolute ICP but, rather, changes in cerebral perfusion pressure (CPP) and brain oxygenation. Lastly, most brain injuries are heterogeneous and the technology does not take these variations into account.

\section{Neurophysiology}

\section{Electroencephalogram}

Numerous studies have explored the concept that neurophysiological changes may actually precede ICP changes in patients with intracranial hypertension ${ }^{32,33}$. Because changes in ICP affect cerebral perfusion, neuronal activity and brain metabolism, some EEG patterns may be useful for ICP monitoring ${ }^{32,33}$. Specific EEG tracings correlate closely with changes in cerebral blood flow (CBF). In particular, changes in ICP correlate significantly with EEG burst duration ${ }^{34}$. Other studies have investigated more complex technologies such as power spectrum analysis ${ }^{35}$, entropy and bispectral index (BIS) and their correlations with CPP and ICP, but no significant applicability within clinical practice was found ${ }^{36}$.

\section{Visual evoked potential}

York et al. ${ }^{37}$ demonstrated a good relationship between ICP elevation and a shift in latency of the $\mathrm{N} 2$ wave of the visual evoked response. The N2 wave is normally found at $70 \mathrm{~ms}$ and corresponds to a cortical phenomenon. It is therefore likely to be sensitive to cerebral cortical injuries and increased ICP. Despite some positive results, Andersson et $a .^{38}$ demonstrated that VEP has a wide range of latencies, amplitudes and waveforms across normal subjects.
In addition, a large proportion of their subjects also had high intra-individual variability over time, which made VEP unreliable as a marker for ICP.

\section{Indirect intracranial pressure estimation}

\section{Pupillometry}

In 1983, Marshall et al. established the fact that the oval pupil represented a stage between the normal pupil and the fixed unreactive pupil of patients with high ICP, and concluded that an oval pupil was indicative of high $\mathrm{ICP}^{39}$. However, their study did not indicate any specific numerical values of ICP correlating with pupillary shape changes. Since then, many studies have been conducted to assess pupillary changes in severely ill patients, to assess their outcome and clinical management. More recently, Chen et al. introduced the neurological pupillary index (NPI) as an early indicator of increased ICP ${ }^{40}$. Quantitative assessment of pupillary reactivity measured using a pupillometer showed excellent accuracy in comparison with invasively measured ICP. However, there still is no direct correlation between NPI and real values of ICP, and pupillometers cannot be used to continuously monitor ICP in intensive care units (ICUs) ${ }^{40}$.

\section{Skull elasticity}

The Monro-Kellie doctrine states that after closure of the fontanelles, the volume inside the cranium remains constant at all times, and that there is no deformation of the skull caused by changes in ICP ${ }^{41,42,43}$. However, questions arising from this assertion have recently created a new avenue of study in the field of ICP monitoring. The notion of measuring minute expansions of the skull as a reflection of increasing ICP was first explored in dogs and cadavers by Pitlyk et al. ${ }^{44}$ in 1985, but the technology that they used did not allow them to go any further. In 2009, Yue and Wang confirmed the previous findings and showed that there was a positive correlation between increasing ICP and skull deformation in rats, with excellent instrument sensitivity ${ }^{45}$.

More recently, a novel noninvasive technology (Brain 4 care $^{\circledR}$ ) was developed to detect very small variations in the volume of the skull caused by changes in ICP, without the need for surgery or even for the patient's head to be shaved. In this device, a strain sensor is placed in contact with the skin surface at the temporoparietal transition, lateral to the sagittal suture ${ }^{46,47}$. Non-invasive contact with the skull is achieved by applying adequate pressure directly on the scalp, using a pin, which requires minimal training. At the current stage of development, the device does not display calibrated pressure values in $\mathrm{mmHg}$, but it can deliver continuous, real-time information about the ICP waveform and, consequently, brain compliance. The information shows great similarity to the curves obtained using invasive methods (Figures 4A and 4B) $)^{46,47,48}$. 
Intracranial pressure waveforms and skull elasticity

In order to better understand this technology, it is important to note that mean ICP is a time-average of the ICP waveform. The ICP waveform consists of three components: respiratory waveforms $(0.1-0.3 \mathrm{~Hz})$ associated with the respiratory cycle, pulse pressure waveforms of frequency equal to the heart rate and slow vasogenic waveforms (e.g. Lundberg $\mathrm{A}$ and $\mathrm{B}$ waves) $)^{2,3}$ (Figure $4 \mathrm{~A}$ ). The pulse pressure waveform is subdivided into three waves: P1 (percussion wave), which represent arterial pulsation transmitted from the choroid plexus; P2 (tidal wave), which reflect rebound pulsations of the brain parenchyma and are a proxy for intracranial compliance; and P3 (dicrotic wave), which represent pressure transmission as a result of aortic valve closure (Figure 4C). Elevated ICP also affects the characteristics of the ICP waveform. For example, an increase in the amplitudes of the three peaks indicates an increase in mean ICP; a reduction in the P1 amplitude suggests decreased cerebral perfusion; and an increase in P2 indicates loss of brain compliance (Figure 4C). Fusion of the peaks P1, P2 and P3 in association with high mean amplitude is an indicator of loss of cerebrovascular autoregulation and loss of cerebral perfusion. In addition, the presence of Lundberg A waves, which are sustained increases in mean ICP lasting 5-20 min, may also signify diminished compliance. Lundberg B waves, which are clustered cyclic elevations in ICP occurring at a rate of 0.33-3 cycles per min with overall cluster duration of 5-30 min, are non-specific indicators of elevated ICP, given that they can also be present in patients with normal $\mathrm{ICP}^{2,3}$.
It is important to emphasize that in this novel technology, monitoring responds promptly to variations in ICP, with either increases or decreases, without delay or rebounds, thus confirming that no bone hysteresis occurs ${ }^{49}$ (i.e. the tendency of a system to preserve a deformation effected by a stimulus). Thus, micrometric deformations of the skull bones that are caused by and correlate linearly with changes in ICP can be detected. Measurements of ICP waveforms using this technology have been made in animal models and in human adults and children ${ }^{50,51,52}$.

\section{OTHER METHODS}

Venous ophthalmodynamometry, which is based on the idea of measuring central retinal vein (CRV) pressure as a surrogate of ICP, was first proposed in $1925^{53}$. However, it was only at the end of the last century that the idea was explored in a study ${ }^{54}$. It was concluded that CRV pressure measurement or ophthalmodynamometry showed good correlation with invasive ICP monitoring. However, this technology is not useful for continuous monitoring. Subsequent refinements to the technology have improved its accuracy (sensitivity of $84.2 \%$ and specificity of $92.8 \%$ ) for predicting raised ICP ${ }^{55}$.

The concept of using tympanic membrane displacement (TMD) as a surrogate for ICP is based on the proximity of the stapes and the oval window. The assumption is that the cochlear fluid pressure, which would be a function

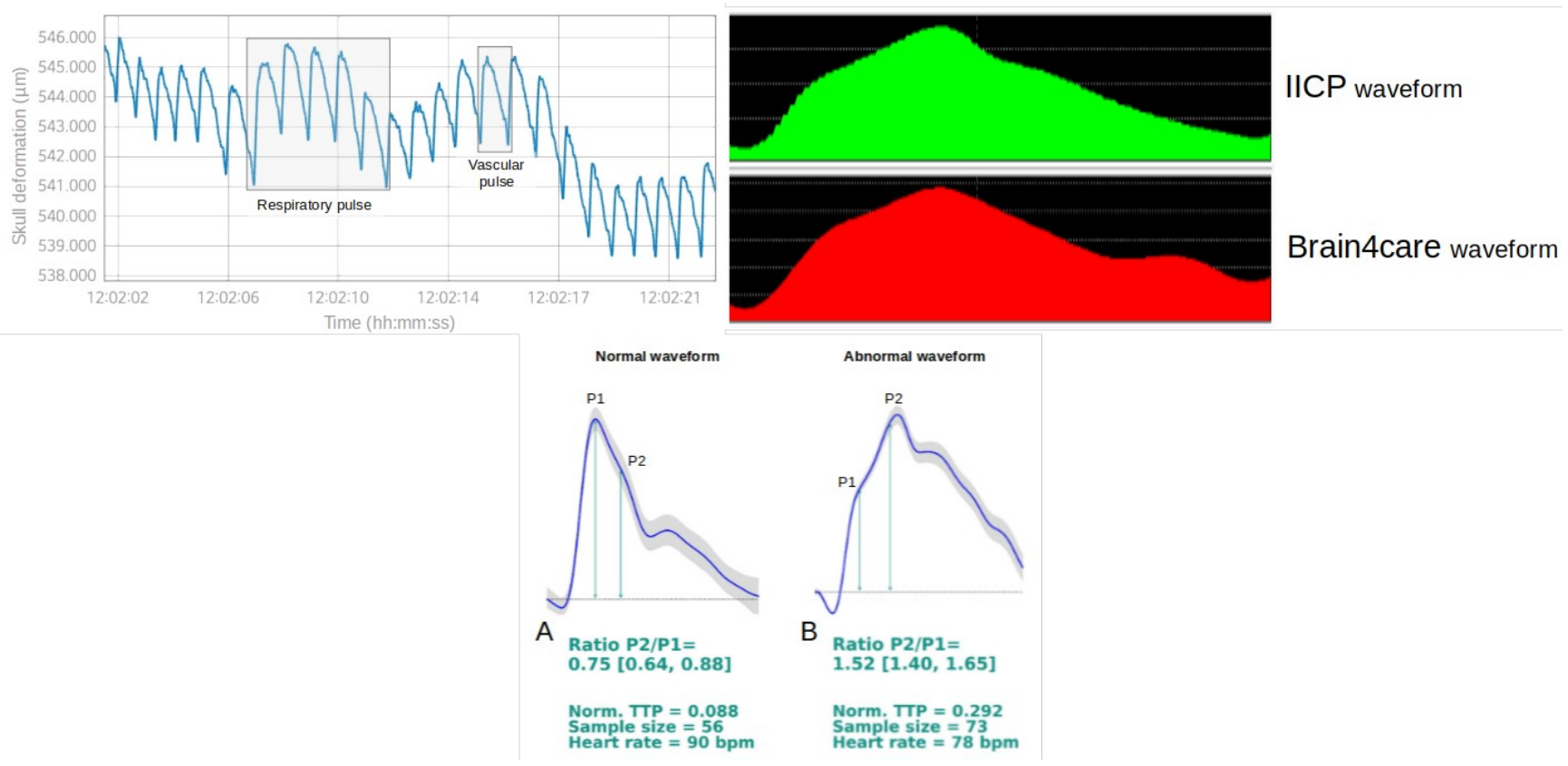

Figure 4. Waveform analysis. (A) Components of the indications for intracranial pressure waveform: pulse pressure waveform and respiratory waveform. (B) Comparison of indications for intracranial pressure waveforms obtained with an invasive sensor (ilCP) and the noninvasive Brain $4 \mathrm{Care}^{\circledR}$ system. (C) indications for intracranial pressure waveforms measured using the Brain4care ${ }^{\circledR}$ sensor. A: normal waveform (P1>P2). B: abnormal waveform (P2>P1). The report provides quantitative information about ICP wave morphology to assist in patient assessment and follow-up. P2/P1 ratio: the ratio between the amplitudes of peaks P2 and P1; TTP: time to peak, defined as the time, from the start of the pulse, at which the ICP waveform reaches its highest peak. 
of the ICP, could affect the stapedial excursions ${ }^{56}$. The evidence available has shown that TMD is a good screening tool that can be useful in assessment and follow-up of patients at risk of increased ICP. However, TMD does not allow establishment of specific ICP values, is not useful for continuous monitoring and requires intact auditory anatomy ${ }^{57,58}$. Another technique that uses the ear as a surrogate for ICP is distortion-product otoacoustic emissions (DPOAE) $)^{59}$. Studies correlating DPOAE with ICP in experimental models and humans have shown good correlation with invasive methods. DPOAE measurements can possibly be an effective tool in non-invasive monitoring of ICP. However, the technique has some limitations: it does not allow absolute measurement of ICP; there is substantial inter-individual variability; and it can only be used in normal-hearing subjects ${ }^{60,61}$.

Tissue resonance analysis ${ }^{62}$ and acoustoelasticity ${ }^{63}$ use the tissue-specific ultrasound resonance of the brain and have shown good correlation with ICP in experimental models. However, there is a scarcity of studies on humans and the level of evidence remains poor.

In infants, the anterior fontanelle is open, and anterior fontanelle pressure monitoring presents a window for measuring ICP noninvasively ${ }^{64,65}$. However, despite multiple studies and various devices used to measure anterior fontanelle pressure, ICP monitoring in infants is currently not feasible in clinical practice through non-invasive methods ${ }^{66}$. Similarly, attempts to correlate intraocular pressure (IOP) with ICP using ocular tonometry, despite its potential, are not supported by the current evidence as a form of noninvasive ICP monitoring ${ }^{67,68,69}$.

\section{DISCUSSION}

The search for a completely noninvasive intracranial pressure (niICP) technique capable of real-time monitoring is the Holy Grail of neurocritical care practice and research ${ }^{1,3}$. If available, it would have a wide range of applications in neurosurgery, neurosciences and translational medicine, from exercise physiology to aerospace medicine.

Despite recent advances that have led to development of various noninvasive techniques for monitoring ICP, the current noninvasive techniques cannot be used as an alternative to the invasive ones ${ }^{70}$. Ideally, a niICP monitoring technique should have the following attributes: to be simple and convenient to use; to depend little on operator experience and bone window; to be readily available throughout the hospital; to provide continuous monitoring; to be quantitative rather than qualitative; track dynamic changes in ICP and CPP; to be less influenced by the patient's cardiovascular instability; and, obviously, to be accurate. All noninvasive techniques have their own advantages and disadvantages, but no method currently satisfies all the criteria for replacing invasive ICP monitoring (Table 5).

Promising prospects include continuously combining noninvasive methods with other clinical or invasive parameters and integrating the data to improve pathophysiological understanding in suspected or confirmed cases of intracranial hypertension. This would help in identifying which types of monitoring can ideally be combined (e.g. oxygenation + compliance+ hemodynamics) and in which clinical setting they can contribute to the care and outcome of neurocritical patients (initial screening and continuous or intermittent monitoring). One limitation of this and other reviews of the topic is the lack of systematic evaluation of the data. In order to perform a systematic review and calculate accuracy between methods, good-quality data comparing all the methods with the gold standard (invasive intracranial pressure monitoring) would be needed. Unfortunately, such data are not available in the current literature ${ }^{2,8,16}$. The challenge of continuous and accurate niICP monitoring remains daunting, but the reward for patients and for science as a whole makes every effort sensible and commendable.

ICP monitoring has become established as a useful method for predicting outcomes and guiding therapy for patients suffering from a range of neurological conditions. In terms of accuracy, reliability and therapeutic options, intraventricular catheter systems still remain the gold standard method. However, with advances in technology, noninvasive monitoring methods have become more relevant. Further evidence is needed before noninvasive ICP monitoring can become a more widespread alternative to invasive techniques.

Table 5. Comparison of the main noninvasive indications for intracranial pressure monitoring methods.

\begin{tabular}{lccccccc}
\hline & CT/MRI & TCD & ONSD & NIRS & Pupillometry & Skull elasticity & EEG \\
\hline Portability & No & Yes & Yes & Yes & Yes & Yes & Yes \\
Operator experience & No & Yes & Yes & No & No & No & Yes \\
Continuous monitoring & No & No & No & No & No & Yes & Yes \\
Cost per patient & Moderate & low & low & low & low & low & low \\
Complications & Yes & No & No & No & No & No \\
\hline
\end{tabular}

CT: computed tomography; MRI: magnetic resonance imaging; TCD: transcranial doppler; ONSD: optic nerve sheath diameter; NIRS: near-infrared spectroscopy; EEG: electroencephalogram. 
1. Shannon FM, Tran A, Cheng W, Rochwerg B, Taljaard M, Kyeremanteng K, et al. Diagnosis of elevated intracranial pressure in critically ill adults: systematic review and meta-analysis. BMJ. 2019 Jul;366:14225. https://doi.org/10.1136/bmj.1422

2. Harary M, Dolmans RGF, Gormley WB. Intracranial pressure monitoring-review and avenues for development. Sensors (Basel). 2018 Feb;18(2):465. https://doi.org/10.3390/s18020465

3. Czosnyka M, Pickard J. Monitoring and interpretation of intracranial pressure. J Neurol Neurosurg Psychiatry. 2004 Jun;75(6):813-21. https://doi.org/10.1136/jnnp.2003.033126

4. Shafi S, Diaz-Arrastia R, Madden C, Gentilello L. Intracranial pressure monitoring in brain-injured patients is associated with worsening of survival. J Trauma. 2008;64(2):335-40. https://doi.org/10.1097/ TA.0b013e31815dd017

5. Chesnut RM, Temkin N, Carney N, Dikmen S, Rondina C, Videtta W, et al. A trial of intracranial-pressure monitoring in traumatic brain injury. N Engl J Med. 2012 Dec;367(26):2471-81. https://doi. org/10.1056/NEJMoa1207363

6. Bekar A, Doğan S, Abaș F, Caner B, Korfali G, Kocaeli H, et al. Risk factors and complications of intracranial pressure monitoring with a fiberoptic device.J Clin Neurosci. 2009 Feb;16(2):236-40. https://doi. org/10.1016/j.jocn.2008.02.008

7. Kasprowicz M, Lalou DA, Czosnyka M, Garnett M, Czosnyka Z. Intracranial pressure, its components and cerebrospinal fluid pressure-volume compensation. Acta Neurol Scand. 2016 Sep;134(3):168-80. https://doi.org/10.1111/ane.12541

8. Raboel PH, BartekJ, Andresen M, Bellander BM, Romne B. Intracranial pressure monitoring: Invasive versus non-invasive methods-a review. Crit Care Res Pract. 2012 Jun;2012:950393. https://doi.org/10.1155/2012/950393

9. Zhang X, Medow JE, Iskandar BJ, Wang F, Shokoueinejad M, Koueik $\mathrm{J}$, et al. Invasive and noninvasive means of measuring intracranial pressure: a review. Physiol Meas. 2017 Jul;38(8):R143-R182. https:// doi.org/10.1088/1361-6579/aa7256

10. Robba C, Bacigaluppi S, Cardim D, Donnelly J, Bertuccio A, Czosnyka M. Non-invasive assessment of intracranial pressure. Acta Neurol Scand. 2016 Jul;134(1):4-21. https://doi.org/10.1111/ ane.12527

11. Pappu S, Lerma J, Khraishi T. Brain CT to assess intracranial pressure in patients with traumatic brain injury. J Neuroimaging. 2016 JanFeb;26(1):37-40. https://doi.org/10.1111/jon.12289

12. Alperin NJ, Lee SH, Loth F, Raksin PB, Lichtor T. MR-intracranial pressure (ICP): A method to measure intracranial elastance and pressure noninvasively by means of MR imaging: baboon and human study. Radiology. 2000 Dec;217(3):877-85. https://doi.org/10.1148/ radiology.217.3.ro0dc42877

13. Marshall LF, Marshall SB, Klauber MR, van Berkum Clark M, Eisenberg $\mathrm{H}$, Jane JA, et al. A new classification of head injury based on computerized tomography. J Neurosurg. 1991 Nov;75 Suppl:S1-S66. https://doi.org/10.3171/SUP.1991.75.1S.0S14

14. Rajajee V, Vanaman M, Fletcher JJ, Jacobs TL. Optic nerve ultrasound for the detection of raised intracranial pressure. Neurocrit Care. 2011 Dec;15(3):506-15. https://doi.org/10.1007/ s12028-011-9606-8

15. Hiler M, Czosnyka M, Hutchinson P, Balestreri M, Smielewski P, Matta $B$, et al. Predictive value of initial computerized tomography scan, intracranial pressure, and state of autoregulation in patients with traumatic brain injury. J Neurosurg. 2006 May;104(5):731-7. https:// doi.org/10.3171/jns.2006.104.5.731

16. Nag DS, Sahu S, Swain A, Kant S. Intracranial pressure monitoring: Gold standard and recent innovations. World J Clin Cases. 2019 Jul;7(13):1535-53. https://doi.org/10.12998/wjcc.v7.i13.1535
17. Rajajee V, Fletcher JJ, Rochlen LR, Jacobs TL. Comparison of accuracy of optic nerve ultrasound for the detection of intracranial hypertension in the setting of acutely fluctuating vs stable intracranial pressure: Post-hoc analysis of data from a prospective, blinded single center study. Crit Care. 2012 May;16(3):R79. https:// doi.org/10.1186/cc11336

18. Agrawal A, Cheng R, Tang J, Madhok DY. Comparison of two techniques to measure optic nerve sheath diameter in patients at risk for increased intracranial pressure. Crit Care Med. 2019 Jun;47(6):e495-e501. https://doi.org/10.1097/ CCM.0000000000003742

19. Swanson JW, Aleman TS, Xu W, Ying G-S, Pan W, Liu GT, et al. Evaluation of optical coherence tomography to detect elevated intracranial pressure in children. JAMA Ophthalmol. 2017 Apr;135(4):320-8. https://doi.org/10.1001/ jamaophthalmol.2017.0025

20. Kalantari H, Jaiswal R, Bruck I, Matari H, Ghobadi F, Weedon J, et al. Correlation of optic nerve sheath diameter measurements by computed tomography and magnetic resonance imaging. Am J Emerg Med. 2013 Nov;31(11):1595-7. https://doi.org/10.1016/j. ajem.2013.07.028

21. Klingelhöfer J, Dander D, Holzgraefe M, Bischoff C, Conrad B. Cerebral vasospasm evaluated by transcranial doppler ultrasonography at different intracranial pressures. $J$ Neurosurg. 1991 Nov;75(5):752-8. https://doi.org/110.3171/ jns.1991.75.5.0752

22. Homburg AM, Jakobsen M, Enevoldsen E. Transcranial doppler recordings in raised intracranial pressure. Acta Neurol Scand. 1993 Jun;87(6):488-93. https://doi.org/10.1111/j.1600-0404.1993. tb04142.x

23. Bellner J, Romner B, Reinstrup P, Kristiansson K-A, Ryding E, Brandt L. Transcranial doppler sonography pulsatility index (PI) reflects intracranial pressure (ICP). Surg Neurol. 2004 Jul;62(1):45-51. https://doi.org/10.1016/j.surneu.2003.12.007

24. Wakerley BR, Kusuma Y, Yeo LL, Liang S, Kumar K, Sharma AK, et al. Usefulness of transcranial Doppler-derived cerebral hemodynamic parameters in the noninvasive assessment of intracranial pressure. J Neuroimaging. Jan- 2015 Feb;25(1):111-6. https://doi.org/10.1111/ jon.12100

25. Zweifel C, Czosnyka M, Carrera E, Deriva N, Pickard JD, Smielewski P. Reliability of the blood flow velocity pulsatility index for assessment of intracranial and cerebral perfusion pressures in head-injured patients. Neurosurgery. 2012 Oct;71(4):853-61. https://doi. org/10.1227/NEU.0b013e3182675b42

26. Schmidt B, Czosnyka M, Schwarze JJ, Sander D, Gerstner W, Lumenta $\mathrm{CB}$, et al. Evaluation of a method for noninvasive intracranial pressure assessment during infusion studies in patients with hydrocephalus. J Neurosurg. 2000 May;92(5):793-800. https://doi. org/10.3171/jns.2000.92.5.0793

27. Cardim D, Robba C, Donnelly J, Bohdanowicz M, Schmidt B, Damian $M$, et al. Prospective study on noninvasive assessment of intracranial pressure in traumatic brain-injured patients: Comparison of four methods. J Neurotrauma. 2016 Apr;33(8):792-802. https://doi. org/10.1089/neu.2015.4134

28. Schoser BG, Riemenschneider N, Hansen HC. The impact of raised intracranial pressure on cerebral venous hemodynamics: a prospective venous transcranial Doppler ultrasonography study. J Neurosurg. 1999 Nov;91(5):744-9. https://doi.org/10.3171/ jns.1999.91.5.0744

29. Ragauskas A, Daubaris G, Dziugys A, Azelis V, Gedrimas V. Innovative non-invasive method for absolute intracranial pressure measurement without calibration. Acta Neurochir Suppl. 2005;95:357-61. https://doi.org/10.1007/3-211-32318-x_73 
30. Kampfl A, Pfausler B, Denchev D, Jaring HP, Schmutzhard E. Near infrared spectroscopy (NIRS) in patients with severe brain injury and elevated intracranial pressure. A pilot study. Acta Neurochir Suppl. 1997;70:112-4. https://doi.org/10.1007/978-3-7091-6837-0_35.

31. Davies DJ, Su Z, Clancy MT, Lucas SJE, Dehghani H, Logan A, et al. Near-infrared spectroscopy in the monitoring of adult traumatic brain injury: a review. J Neurotrauma. $2015 \mathrm{Jul} ; 32(13): 933-41$. https://doi.org/10.1089/neu.2014.3748

32. Amantini A, Carrai R, Lori S, Peris A, Amadori A, Pinto F, Grippo A. Neurophysiological monitoring in adult and pediatric intensive care. Minerva Anestesiol. 2012 Sep;78(9):1067-75.

33. Amantini A, Fossi S, Grippo A, Innocenti P, Amadori A, Bucciardini L, et al. Continuous EEG-SEP monitoring in severe brain injury. Neurophysiol Clin. 2009 Apr;39(2):85-93. https://doi.org/10.1016/j.neucli.2009.01.006

34. Connolly M, Vespa P, Pouratian N, Gonzalez NR, HuX. Characterization of the relationship between intracranial pressure and electroencephalographic monitoring in burst-suppressed patients. Neurocrit Care. 2015 Apr;22(2):212-20. https://doi. org/10.1007/s12028-014-0059-8

35. Chen H, Wang J, Mao S, Dong W, Yang H. A new method of intracranial pressure monitoring by EEG power spectrum analysis. Can J Neurol Sci. 2012 Jul;39(4):483-7. https://doi.org/10.1017/ s0317167100013998

36. Sharbrough FW, Messick JM Jr, Sundt TM Jr. Correlation of continuous electroencephalograms with cerebral blood flow measurements during carotid endarterectomy. Stroke. 1973 JulAug;4(4):674-83. https://doi.org/10.1161/01.str.4.4.674

37. York D, Legan M, Benner S, Watts C. Further studies with a noninvasive method of intracranial pressure estimation. Neurosurgery. 1984 Apr;14(4):456-61. https://doi. org/10.1227/00006123-198404000-00011

38. Andersson L, Sjolund J, Nilsson J. Flash visual evoked potentials are unreliable as markers of ICP due to high variability in normal subjects. Acta Neurochir (Wien). 2012 Jan;154(1):121-7. https://doi. org/10.1007/s00701-011-1152-9

39. Marshall LF, Barba D, Toole BM, Bowers SA. The oval pupil: Clinical significance and relationship to intracranial hypertension. J Neurosurg. 1983 Apr;58(4):566-8. https://doi.org/10.3171/ jns.1983.58.4.0566

40. Chen JW, Gombart ZJ, Rogers S, Gardiner SK, Cecil S, Bullock RM. Pupillary reactivity as an early indicator of increased intracranial pressure: The introduction of the Neurological Pupil index. Surg Neurol Int. 2011;2:82. https://doi.org/10.4103/2152-7806.82248

41. Monro A. Observations on the structure and functions of the nervous system. Edinbourgh, UK: Creech and Johnson; 1783.

42. Kellie G. Appearances observed in the dissection of two individuals; death from cold and congestion of the brain. Trans. Med.-Chir. Soc. Edinbrugh. 1824;1:84.

43. Cushing $\mathrm{H}$. The third circulation in studies in intracranial physiology and surgery. London, UK: Oxford University Press; 1926.

44. Pitlyk PJ, Piantanida TP, Ploeger DW. Noninvasive intracranial pressure monitoring. Neurosurgery. 1985 Oct;17(4):581-4. https://doi. org/10.1227/00006123-198510000-00008

45. Yue LW. Deformation of skull bone as intracranial pressure changing. African J Biotechnol. 2009 Mar;8(5):745-50. https://doi.org/10.5897/ AJB2009.000-9126

46. Vilela GH, Cabella B, Mascarenhas S, Czosnyka M, Smielewski P, Dias $\mathrm{C}$, et al. Validation of a new minimally invasive intracranial pressure monitoring method by direct comparison with an invasive technique. Acta Neurochir Suppl. 2016;122:97-100. https://doi. org/10.1007/978-3-319-22533-3_19

47. Mascarenhas S, Vilela GHF, Carlotti C, Damiano LEG, Seluque W, Colli B, et al. The new ICP minimally invasive method shows that the Monro-Kellie doctrine is not valid. Acta Neurochir Suppl. 2012;114:117-20. https://doi.org/10.1007/978-3-7091-0956-4_21
48. Gomes I, Shibaki J, Padua B, Silva F, Gonçalves T, Spavieri-Junior DL, et al. Comparison of Waveforms Between Noninvasive and Invasive Monitoring of Intracranial Pressure. Acta Neurochir Suppl. 2021;131:135-40. https://doi.org/10.1007/978-3-03059436-7_28

49. Noori HR. Examples of Hysteresis Phenomena in Biology. In: Hysteresis Phenomena in Biology. Springer Briefs in Applied Sciences and Technology., Berlin, Heidelberg: Springer; 2014.

50. Bollela VR, Frigieri G, Vilar FC, Spavieri Jr DL, Tallarico FJ, Tallarico GM, et al. Noninvasive intracranial pressure monitoring for HIVassociated cryptococcal meningitis. Braz J Med Biol Res. 2017 Aug;50(9):e6392. https://doi.org/10.1590/1414-431×20176392

51. Ballestero MFM, Frigieri G, Cabella BCT, de Oliveira SM, de Oliveira RS. Prediction of intracranial hypertension through noninvasive intracranial pressure waveform analysis in pediatric hydrocephalus. Childs Nerv Syst. 2017 Sep;33(9):1517-24. https://doi.org/10.1007/ s00381-017-3475-1

52. Frigieri G, Andrade RAP, Dias C, Spavieri Jr DL, Brunelli R, Cardim DA, et al. Analysis of a Non-invasive intracranial pressure monitoring method in patients with traumatic brain injury. Acta Neurochir Suppl. 2018;126:107-10. https://doi.org/10.1007/978-3-319-65798-1_23

53. Golzan SM, Avolio A, Graham SL. Hemodynamic interactions in the eye: a review. Ophthalmologica. 2012 Oct;228(4):214-21. https://doi. org/10.1159/000342157

54. Firsching R, Schütze M, Motschmann M, Behrens-Baumann W. Venous opthalmodynamometry: a noninvasive method for assessment of intracranial pressure. J Neurosurg. $2000 \mathrm{Jul} ; 93(1)$ :336. https://doi.org/10.3171/jns.2000.93.1.0033

55. Firsching R, Müller C, Pauli SU, Voellger B, Röhl FW, BehrensBaumann W. Noninvasive assessment of intracranial pressure with venous ophthalmodynamometry. Clinical article. J Neurosurg. 2011 Aug;115(2):371-4. https://doi. org/10.3171/2011.3.JNS101275

56. Marchbanks RJ. Measurement of tympanic membrane displacement arising from aural cardiovascular activity, swallowing, and intraaural muscle reflex. Acta Otolaryngol. Jul-Aug 1984;98(1-2):119-29. https://doi.org/10.3109/00016488409107543

57. Reid A, Marchbanks RJ, Burge DM, Martin AM, Bateman DE, Pickard JD, et al. The relationship between intracranial pressure and tympanic membrane displacement. Br J Audiol. 1990 Apr;24(2):1239. https://doi.org/10.3109/03005369009077853

58. Samuel M, Burge DM, Marchbanks RJ. Tympanic membrane displacement testing in regular assessment of intracranial pressure in eight children with shunted hydrocephalus.J Neurosurg. 1998 Jun;88(6):983-95. https://doi.org/10.3171/jns.1998.88.6.0983

59. Bershad EM, Urfy MZ, Pechacek A, McGrath M, Calvillo E, Horton $\mathrm{NJ}$, et al. Intracranial pressure modulates distortion product otoacoustic emissions: a proof-of-principle study. Neurosurgery. 2014 Oct;75(4):445-54; discussion 454-5. https://doi.org/10.1227/ NEU.0000000000000449

60. Voss SE, Horton NJ, Tabucchi TH, Folowosele FO, Shera CA. Postureinduced changes in distortionproduct otoacoustic emissions and the potential for noninvasive monitoring of changes in intracranial pressure. Neurocrit Care. 2006 Jun;4(3):251-7. https://doi. org/10.1385/NCC:4:3:251

61. Buki B, Avan P, Lemaire JJ, Dordain M, Chazal J, Ribari O. Otoacoustic emissions: a new tool for monitoring intracranial pressure changes through stapes displacements. Hear Res 1996;2:125-39.

62. Michaeli D, Rappaport ZH. Tissue resonance analysis; a novel method for noninvasive monitoring of intracranial pressure. Technical note. J Neurosurg. 2002 Jun;96(6):1132-7. https://doi. org/10.3171/jns.2002.96.6.1132

63. Wu J, He W, Chen WM, Zhu L. Research on simulation and experiment of noninvasive intracranial pressure monitoring based on acoustoelasticity effects. Med Devices (Auckl). 2013 Aug;6:123-31. https://doi.org/10.2147/MDER.S47725 
64. Bunegin L, Albin MS, Rauschhuber R, Marlin AE. Intracranial pressure measurement from the anterior fontanelle utilizing a pneumoelectronic switch. Neurosurgery. 1987 May;20(5):726-31. https://doi.org/10.1227/00006123-198705000-00009

65. Horbar JD, Yeager S, Philip AG, Lucey JF. Effect of application force on noninvasive measurements of intracranial pressure. Pediatrics. 1980 Sep;66(3):455-7.

66. Wiegand C, Richards P. Measurement of intracranial pressure in children: a critical review of current methods. Dev Med Child Neurol. 2007 Dec;49(12):935-41. https://doi.org/10.1111/j.1469-8749.2007.00935.x

67. Sheeran P, Bland JM, Hall GM. Intraocular pressure changes and alterations in intracranial pressure. Lancet. 2000 Mar;355(9207):899. https://doi.org/10.1016/s0140-6736(99)02768-3
68. Sajjadi SA, Harirchian MH, Sheikhbahaei N, Mohebbi MR, Malekmadani $\mathrm{MH}$, Saberi $\mathrm{H}$. The relation between intracranial and intraocular pressures: study of 50 patients. Ann Neurol. 2006 May;59(5):867-70. https://doi.org/10.1002/ana.20856

69. Li Z, Yang Y, Lu Y, Liu D, Xu E, Jia J, et al. Intraocular pressure vs intracranial pressure in disease conditions: a prospective cohort study (Beijing iCOP study). BMC Neurol. 2012 Aug;12:66. https://doi. org/10.1186/1471-2377-12-66

70. Brain Trauma Foundation; American Association of Neurological Surgeons; Congress of Neurological Surgeons. Guidelines for the management of severe traumatic brain injury. J Neurotrauma. 2007;24 Suppl 1:S1-106. https://doi. org/10.1089/neu.2007.9999 